\title{
JOHANN GOTTLIEB FICHTE, LA EDUCACIÓN Y LA INTERCULTURALIDAD
}

\author{
[JOHANN GotTLIEB Fichte, EDUCATION AND INTERCULTURALITY]
}

\author{
Gerardo Miguel Nieves-Loja * \\ Universidad Nacional de Chimborazo, Ecuador
}

\begin{abstract}
RESUMEN: Esta investigación trata de realizar un análisis crítico y comparativo de la propuesta educativa del filósofo alemán Johann Gottlieb Fichte (1762-1814); quien manifiesta un vivo interés por la educación y la política, con la pretensión de recuperar y liberar a la nación alemana de los extranjeros. Según Fichte, una educación auténtica consiste en que los estudiantes deben ser alejados del mundo de los adultos para vivir en una morada más pura, donde aprendan a vivir con honor y sean capaces de inventar máquinas y herramientas. No son importantes las palabras y el debate en el espacio público. En contraste, se analiza la propuesta de Hannah Arendt, quien considera que toda educación debe despertar la opinión y la participación ciudadanas en el espacio público. El estudiante no debe ser alejado del mundo para fabricar y vender (homo faber); al contrario, debe aprender a pensar por sí mismo y actuar de manera concertada. En este sentido, los discursos contemporáneos sobre la interculturalidad, mediante un diálogo de saberes, constituyen una alternativa de paz y armonía entre las diferentes culturas.
\end{abstract}

Palabras-Clave: educación; culturas; interculturalidad; nacionalismo; público-privado
ABSTRACT: This research tries to perform a critical and comparative analysis of the educational proposal of the German philosopher Johann Gottlieb Fichte (17621814); who expresses a keen interest in education and politics, with the aim of recovering and liberating the German nation from foreigners. According to Fichte, an authentic education is that students must be removed from the world of adults to live in a purer residence, where they learn to live with honor and are able to invent machines and tools. Words and debate in the public space are not important. In contrast, Hannah Arendt's proposal is analyzed, who believes that all education should arouse citizen opinion and participation in the public space. The student must not be removed from the world to manufacture and sell (homo faber); On the contrary, he must learn to think for himself and act in concert. In this sense, contemporary discourses on interculturality, through a dialogue of knowledge, constitute an alternative of peace and harmony between different cultures.

KEYwORDS: education; cultures; interculturality; nationalism; public-private

\section{INTRODUCCIÓN}

Johann Gottlieb Fichte (1762-1814) fue un filósofo alemán proveniente de una familia de campesinos pobres que, gracias al apoyo económico del barón Von Militz, pudo iniciar sus estudios de teología que luego abandonaría a causa de la disminución del apoyo de parte de su benefactor. Para superar esta dificultad económica,

* Doctor (PhD) en Filosofia por la Universidad de Estrasburgo - Francia. Actualmente es docente - investigador de la Universidad Nacional de Chimborazo - Ecuador, en la Facultad de Ciencias Politicas y Administrativas; además es Coordinador de Publicaciones de la misma Universidad.E-mail: gnieves@unach.edu.ec/gnievesloja@yahoo.es 
Fichte trabaja como preceptor y, posteriormente, visita a Kant para presentarle su libro: Ensayo de una crítica de toda revelación (Versuch einer kritik aller offenbarung, 1792). Este es el libro que lo llevó a la fama y luego fue contratado, con el apoyo de Goethe, como profesor de filosofía en la Universidad de Jena. Posteriormente, abandonaría esta Universidad acusado de ateísmo por la posición filosófica que asumió; esto hizo que se 192 trasladara a Berlín, donde trabajó como preceptor privado para poder sobrevivir. Es la época en que Berlín está ocupada por Napoleón, Fichte escribe Discursos a la nación alemana (Reden an die deutsche Nation, 1808), donde plantea sus argumentaciones políticas y educativas a favor de una Alemania que se encontraba ocupada por Francia.

Fichte, para algunos analistas fundador de la filosofía moderna, es un pensador riguroso y abstracto, como se puede descubrir en su libro: Teoría de la ciencia, el cual es una reflexión sobre la libertad, obra que mereció un alto reconocimiento por parte de Hegel. La ciencia es la ciencia filosófica, y es la única que puede dar sentido a todas las aspiraciones de la imaginación humana. Según Fichte, el conocimiento se fundamenta en el sujeto y no en los fenómenos, como afirmaba Kant. Fichte señala:

Atiende a ti mismo: vuelve tu mirada de todo lo que rodea a tu interior - esta es la primera exigencia de la filosofía a su aprendiz. No se habla de nada que esté fuera de ti mismo, sino únicamente de ti mismo (1984, p. 84).

Se puede constatar que el pensamiento de Fichte se centra en el "yo absoluto". El conocimiento se manifiesta en las categorías del "yo" y el "no yo". El "yo" es la conciencia del hombre, es el absoluto, es la única realidad, la razón, la voluntad; el conocimiento y la acción que constituyen la razón de nuestro ser (Fichte, 2009). Este "yo absoluto" es el creador de la historia humana y de la actividad moral de la conciencia; además, es infinito e ilimitado. En contraste, se encuentra el "no yo", el "otro" (Reale y Antiseri, 1992), el cual es fabricado, el no absoluto; es finito y limitado; es la corporeidad, el "yo empírico". Entre el "yo absoluto" y el "no yo relativo", no hay cabida para la trascendencia. Esto condujo a que Fichte fuera acusado de ateísmo al considerar la religión como una praxis moral y afirmar que Dios no existe, "pertenece al mundo de lo suprasensible y se trata de alguien que no tiene sensibilidad" (1977, p. 25).

Fichte se encuentra en Königsberg, y es ahí donde se dedica al estudio profundo del pensamiento del pedagogo suizo Pestalozzi. Es, en esta obra, donde Fichte encuentra su inspiración considerándola como "el verdadero instrumento salvador de la humanidad enferma" (1977, p. 35); entonces escribe Discursos a la nación alemana, donde pretende recuperar y renovar a Alemania a través del sistema educativo conduciéndola a una verdadera liberación. Todo el proyecto educativo se hará en el marco de la lengua alemana. Fichte inserta una nueva idea de Europa federalista, haciendo que lo jurídico, lo político y la economía se vinculen al aspecto cultural y educativo, trayendo consecuencias para el hombre moderno dedicado a la fabricación, pero despojado del ámbito de lo público. Quizá parezca injusto leer a Fichte a la luz de estudios contemporáneos de pedagogía, antropología y filosofía; sin embargo, se considera que es oportuno debido al altísimo impacto que tuvo Fichte en la educación alemana y europea y, que, incluso, llegó a América Latina.

Se puede, entonces, preguntar: ¿Cuáles son los riegos de una educación orientada únicamente al yo interior dejando de lado el espacio público? ¿Es posible llevar a cabo una educación liberadora donde se integre a los otros a los excluidos? ¿Cuáles serían los riesgos de una educación dirigida por un Estado totalitario? ¿Es posible hablar de una educación intercultural para el mundo contemporáneo? ¿Cuáles serían los temas prioritarios de una educación intercultural? 
En la reflexión que sigue, se trata de analizar los siguientes aspectos: inicio con la presentación del pensamiento pedagógico de Fichte, los riesgos que se presentan al reducir y caer en un idealismo absoluto donde se prioriza al yo interior del espacio privado. Se pasa luego a analizar la amenaza que representa una educación nacionalista donde se mire con desconfianza a quienes provienen de otras culturas Enseguida, se presenta la reacción de un Estado totalitario y la educación. Por último, se ofrece el análisis de lo que podría ser una educación intercultural.

\section{EDUCAR CIUDADANOS PARA EL ESPACIO PRIVADO. LA PRIORIDAD DEL YO INTERIOR}

Fichte, un asiduo lector de Kant, cuestiona una educación basada únicamente en el "buen orden" y la "moralidad", proponiendo, de manera alternativa, un sistema educativo que forme las emociones, los impulsos vitales; deben existir normas que eliminen la libertad de la voluntad. Más bien, en los educandos, deben potenciarse las voluntades firmes y seguras. Fichte está seguro de que esto no se consigue con exhortaciones, sino que se deben ejercitar, desarrollar y fortalecer aquellos elementos que impulsan el espíritu de los educandos. El amor es el impulso vital (1977). Sin embargo, según Kant, la voluntad no es una capacidad mental distintita del pensar, sino que se trata de la razón práctica (Arendt, 2005). Únicamente la razón es la que determina la voluntad de los hombres de acción, y ésta, no es patrimonio de los pensadores profesionales que se consagran al bios theôrêtikos, que se dedican únicamente a interpretar y no a cambiar. Los hombres deben innovar para construir la libertad; se trata más del yo puedo que del yo quiero. La libertad y el poder son sinónimos y condiciones para la pluralidad humana (p. 454), la cual nunca debe perder la espontaneidad. Se puede constatar que, tanto Fichte como Arendt, son grandes lectores de la obra de Kant; sin embargo, es Arendt quien considera que el yo puedo con los otros, es mucho más importante que el yo quiero autónomo de Kant, del cual Fichte es partidario.

Según Fichte, la educación debe formar hombres nuevos en su interior, no hay que hacer copias, sino, más bien, fomentar actividades de creación espiritual; además, se debe formar hombres que sean capaces de engendrar "conocimiento de leyes generales y de validez universal” (1977, p. 76). Toda esta propuesta educativa se apoya en un verdadero placer de aprender que debe tener el educando. Aquí se puede constatar el idealismo absoluto del cual Fichte es su promotor, ya que los educandos no deben preocuparse de los otros seres humanos, de los problemas del mundo, sean políticos, sociales o culturales. Ellos deben priorizar sus asuntos íntimos, personales, es decir, privados.

Más aun, en el análisis de Fichte, la educación no debe coartar ni reprimir la espontaneidad espiritual de los educandos; al contrario, hay que estimularla directamente, ésta es la base para producir conocimiento trascendental, permitiendo al estudiante pensar, y no solo de memorizar y recibir pasivamente el conocimiento. Tal experiencia no debe provocar un gozo material sino espiritual, siendo vivenciado de manera apartada de lo común y dejando de lado todo deseo de bienestar personal. Este proyecto educativo de Fichte debe "formar excelentes trabajadores de las ciencias" (1977, p. 75), en el cual el educando, mediante el amor, sea capaz de esbozar de manera libre una imagen de un orden moral para su vida según las leyes de la razón, y no debe expresarse solamente en palabras sino en los hechos. Paran Fichte, la educación debe velar por la educación de los jóvenes sin el contacto con los adultos y sin otra 
educación. De esta manera se evita que se corrompan y mal formen. Los estudiantes deben ser alejados del mundo (adultos), para vivir en una "morada más pura" (1977, p. 197).

Las afirmaciones de Fichte muestran claramente que los alumnos de la nueva educación deben ser separados de la comunidad de adultos, formando una sociedad separada, solo para ellos, sintiéndose obligados solo en su interior. El análisis educativo de Fichte tiene repercusiones políticas muy significativas en los educandos debido a que continúa separándoles del espacio público al hacer que se preocupen solamente de los asuntos ontológicos y metafísicos de la existencia humana. La vida interior y no el espacio público es prioritario, esto significa que deben cerrar sus ojos al mundo para preocuparse de su yo existencial; cada uno debe concentrarse en fabricar objetos de manera solitaria, debe preocuparse por ser excelentes trabajadores y no por ser excelentes ciudadanos que participan del debate público. La educación Fichtiana no valora la palabra y la opinión; los estudiantes no son capaces de crear e innovar su opinión sobre el mundo. Se constata esta situación en la actualidad con el advenimiento de la era virtual, la palabra ha caído en desuso, vivimos la era del silencio. Fichte con su propuesta pedagógica, lo que hace es continuar con la tradición de la Grecia clásica de Platón, Aristóteles y Jenofonte, para quienes los niños debían ser separados no solo de los adultos, sino también de su familia y de su ciudad, donde existía la libertad ciudadana (polis). La finalidad era que los niños no se contagiaran del mundo de los adultos y de los esclavos.

Fichte afirma que los estudiantes deben realizar ejercicios físicos, trabajos manuales y labores agrícolas, donde el que más sobresale, puede ejercer la responsabilidad de ser supervisor de sus compañeros. El objetivo del estudiante es estudiar y trabajar. Todos son iguales en el trabajo y en la diversión. Nadie alaba a nadie ya que todos hacen lo que tienen que hacer. Lo importante es cumplir con el deber, en esto consiste la alegría. Además, en esta constitución, "el más capaz debe permanecer despierto cuando sus compañeros descansan, y debe dedicarse a pensar y meditar, cuando sus compañeros se encuentran jugando" (1977, p. 77). La educación debe realizarse mediante un método y unas normas fijas para, de esta manera, "obtener resultados favorables" (p. 81).

La educación que plantea Fichte corresponde al advenimiento del hombre de la modernidad, donde desaparece la distinción entre lo privado y lo público y se lleva a cabo el ascenso de lo social. Se forma a los ciudadanos para que sean buenos trabajadores y empleados dedicados a las actividades económicas. El riesgo de esta educación, según Hannah Arendt (2002), es que se forman individuos para una sociedad de masas que, luego, mediante un sistema de propaganda, serán presa fácil para los estados totalitarios. La libertad política pierde importancia.

El planteamiento de Fichte corresponde al dominio de lo privado, ya que la vida humana no trasciende, los hombres viven en sociedad y fabrican un mundo solo para habitar. Los educandos son formados para obedecer y no son visibilizados por la sociedad de adultos, por cuanto se encuentran separados. Este tipo de educación recurre al temor y a la fuerza (violencia) para provocar miedo y hacerse obedecer, características que son propias de los estados totalitarios como el instaurado por Hitler. Cabe recordar también que, es en el siglo XVIII, cuando el concepto de cultura sufre un cambio en su comprensión: lo que antes, en lugares como Grecia y Roma clásicas, era el cultivo de las artes y de la ciencia, se transformó en actos de salón, de modales y de comportamientos propios de la sociedad burguesa de aquella época. Finalmente, la educación que plantea Fichte es aquella donde todos constituyen una enorme familia teniendo las mismas actitudes, los mismos intereses y las mismas opiniones; todos 
piensan igual, lo homogéneo pasa a constituirse como virtud (Arendt, 2002). Sin embargo, el problema más grave es cuando se educa a alguien en contra de, es decir, que los otros, los extranjeros, son una amenaza para mí. Hitler hizo creer a los alemanes que los judíos preparaban una conspiración mundial, por ende, había que evitarla dándoles muerte.

\section{DE UNA EDUCACIÓN NACIONALISTA A UNA EDUCACIÓN LIBERADORA}

Fichte considera como antinatural el hecho de que los alemanes sean dirigidos por extranjeros. Además, decía: "hay que educar a la mayoría de los ciudadanos en una mentalidad patriótica, $(. .$.$) , ya que solamente la educación, y ningún otro medio podrá$ salvar Alemania" (1977, p. 176). Los alemanes "deben ser educados para la mayoría de edad y deben luchar por Alemania, ya que esta ha perdido su sede" (p. 177), y justamente debe recuperar "con vigor juvenil para devolver al Estado la independencia perdida" (p. 178); pero no solamente con palabras, debido a su carácter intrascendente, sino con hechos. Fichte considera que el amor a la patria alemana es el componente fundamental, de aquí surge el ciudadano defensor de la patria alemana, como también el ciudadano autentico y pacífico.

Se puede constatar, entonces, que el idealismo absoluto de Fichte no da cabida al otro, no permite la alteridad, al extranjero; peor aún, no considera la propuesta de una ética que implique el ponerse en el lugar del otro, lo cual conduciría a establecer un diálogo y unas relaciones pacíficas de entendimiento (Córdoba y Vélez de la Calle, 2015). Se trata, distinto a lo que piensa Fichte, del reconocimiento del otro como alguien distinto a mí. En este sentido, se trata de dos concepciones del mundo y de la vida distintos y, en el caso de que exista alteridad, habrá una relación de integración y armonía, ya no del dominio del uno sobre el otro. Según el filósofo francés Levinas (2004), el otro tiene un rostro que se comunica, es el hermano que sufre, que debe provocar y despertar en $m i$ actitudes de solidaridad y no de indiferencia.

Luego, el modelo educativo de Fichte afirma que la capacidad cognoscitiva del educando debe estar fundamentada en "el amor por el objeto conocido" (1977, p. 190), en el ámbito de una comunidad razonable, donde exista la unidad y la igualdad de convicciones. No es fundamental la erudición, sino, más bien, "el respeto, la ética, la justicia, la bondad, lo veraz y el autodominio" (p.191). Además, deben aprender también a desapegarse de lo material, como también de los elogios o la desaprobación de los demás, y ser completamente indiferentes a la opinión de los otros, es decir, autosuficientes y autodeterminantes. Los educandos deben vivir únicamente con sus compañeros estudiantes y sus maestros, donde ellos aprenden a vivir con honor y a trabajar en el cultivo de la tierra. "Deben ser capaces de inventar máquinas y herramientas" (1977, p. 199). Según Fichte, "la utilización del temor no representa ningún perjuicio para la moralidad del educando" (p. 76).

Fichte insiste en que los estudiantes deben vivir juntos acompañados de sus maestros, su relación es simplemente compartir actividades; sin embargo, el ideal de una comunidad, en este caso educativa, debe ser un espacio donde se actúa juntos, se hablan los unos con los otros; es el espacio donde se aprende a lidiar con los diferentes, los extranjeros. Este espacio común (koinon), debe componerse de diversos puntos de vista, donde los estudiantes aprenden a argumentar y a persuadir, es decir, aprenden a ser críticos y a ejercer su libertad cuando toman la palabra y expresan lo que piensan (Arendt, 2010). Son necesarios, entonces, la valentía y el coraje para hacer frente a las dificultades. 
La educación erudita del futuro científico, según Fichte, consiste en la educación nacional general, donde el educando desarrolla el "conocimiento sensitivo e intuitivo", maneja conceptos, tiene ideas innovadoras e incluso se adelanta al futuro y domina la lengua alemana. Además, posee una espontaneidad espiritual y es capaz de reflexionar en solitario, y se dedica al estudio de la materia de su futura profesión. El hombre común, no erudito, se dedica a conocimientos generales y al cultivo de la tierra, a las artes mecánicas y prácticas manuales (1977, p. 201).

Se puede ver, entonces, que Fichte prioriza la educación del individuo en detrimento del aspecto comunitario (Dussel, 2018). La comunidad es el espacio donde se aprende a escuchar y a crear, como también a expresarse. Además, la educación debe ser liberadora y transformadora de cualquier opresión. En este sentido, ha sido el pedagogo brasileño Paulo Freire (1921-1997), quien planteó una nueva manera de educar partiendo de los lugares de pobreza y de la cultura de los educandos. Es bien conocido el notable aporte de Freire a la educación en el mundo; incluso, influyó enormemente en la educación de adultos en España, sobre todo a partir de los años cincuenta, cuando la tasa de analfabetismo en España era del 34\% (Groves, 2016). Posteriormente, a partir de los años sesenta, los centros urbanos recibieron una considerable migración de personas provenientes del sector rural, estableciéndose como lugares privilegiados para los movimientos de docentes. Fueron los espacios donde se difundían las obras de Freire, quien se constituyó en un paradigma de la educación de los marginados. Todo se basaba en el diálogo de docentes con estudiantes acerca de su vida cotidiana.

Fichte no es defensor de una educación popular, es más bien defensor de una educación nacional, de manera que se pueda rescatar de la miseria al pueblo alemán a través del estímulo de la "actividad espiritual del educando" (1977, p. 180). Para Freire, en cambio, la educación popular trata de que las personas, los excluidos, salgan de la cultura del silencio, que se liberen de los mecanismos de dominación que les impide expresarse. Ellos deben tomar la palabra en el espacio público, son los constructores del conocimiento. De esta manera, las diferentes culturas que se encuentran en el aula inician un proceso de interculturalidad mediante el compartir de las diferentes visiones orales y escritas de los educandos (De Souza, 2007). En la Educación como práctica de la libertad, Freire considera fundamental el concepto de cultura, el cual está unido a los procesos de globalización que terminan alienando a las personas, quienes podrán ser liberadas mediante el método del diálogo en las reuniones del pueblo. Tanto el educador como el educando, aprenden y construyen conocimiento mutuamente (Lucio-Villegas, 2015). Además, se pueden crear círculos de investigación, donde se discuta y se aborden temas de manera interdisciplinar, con el objetivo prioritario de concienciar liberándose así de las causas de la alienación.

Los estudiantes, mediante un proceso de diálogo con su maestro, construyen conocimiento; ya no es la pedagogía de la época clásica del que enseña y del otro que aprende, que repite lo que el maestro enseña; al contrario, el educando aporta desde sus conocimientos culturales, sociales y políticos al engrandecimiento de un saber. Cada cultura tiene sus discursos y sabidurías mediante los cuales enriquece a los demás; incluso, en estos espacios no hay solamente un idioma, que es la exigencia de Fichte, al contrario, en esta experiencia es bienvenida otra experiencia de vida, otro saber, se lleva a cabo un enriquecimiento mutuo, todos aprenden de todos. La educación liberadora es comunitaria, va más allá de las fronteras idiomáticas y demás requisitos, como la edad, para dar acogida a todos aquellos que no han tenido la oportunidad de avanzar en su educación.

Sin embargo, el enemigo principal de una educación liberadora es el Estado 
totalitario, el cual reduce a una unidad política, donde se piensa de una única manera, y se repiten slogans a favor de quien está en el poder. Los estados totalitarios tienen una forma muy particular de educar (adoctrinar) a sus súbditos, pretendiendo que tengan los mismos comportamientos y una única manera de pensar y de actuar.

\section{EDUCACIÓN Y ESTADO TOTALITARIO}

Fichte considera que una sociedad correctamente organizada no requiere de la religión para estructurar de mejor manera la vida, es suficiente la ética. La religión no es praxis, es conocimiento; ésta ayuda al ser humano a comprenderse a sí mismo, y, sobre todo, ayuda a mejorar sociedades corruptas e inmorales. "La religión es solamente la entrega a una ley superior" (1977, p. 85). Quien se encarga de la ejecución de este plan educativo de Fichte no es la Iglesia. Fichte, fue acusado de ateísmo, al desconfiar de una educación confesional. Sin embargo, hay la posibilidad de un cristianismo policéntrico, encargado de buscar la verdad en otras culturas, con una actitud de diálogo y escucha renunciando a la sacralización de su origen (FornetBetancourt, 2015). Causa gran dificultad la eliminación del tema religioso en sociedades profundamente religiosas, y no se trata solamente del islamismo, ya que, incluso la filosofía trascendental clásica de Alemania, es heredera de su pasado confesional, que influyó incluso en el mismo Kant. Sin embargo, en el caso de América Latina, es posible hablar de la teología y la filosofía de la liberación que constituyen discursos alejados del neoplatonismo, de lo mercantil y lo esotérico. Es posible un dialogo entre filosofía y religión, $\mathrm{y}$, sobre, todo entre filosofía y educación (Berisso \& Giuliano, 2015).

Según Fichte, cada individuo debe ser entrenado para defender al Estado, el cual puede disponer de los ciudadanos para defenderse de los enemigos. Ningún enemigo será capaz de derrotar un Estado que dispone de gente acostumbrada desde su juventud a reflexionar y a valerse por sí misma (1997). Llama la atención que un discurso muy parecido se encuentra en la teoría política de Carl Schmitt, cuando otorga al Estado (en su versión totalitaria) la "facultad de declarar quien es amigo y quien es enemigo de la nación, al que hay que combatirlo y expulsarlo fuera de la unidad política” (2009, p 57). Esta manera de comprender lo político provoca un choque, una confrontación entre quienes están a favor y quienes están en contra. No así Hannah Arendt, quien aboga por estados que defienden la vida de los ciudadanos, los cuales están llamados a participar en el espacio público, tanto en palabras como en acciones, siendo, asimismo, los encargados de reconstruir la comunidad política plural.

Fichte critica al Estado que se ha dedicado únicamente a las instituciones policiales y judiciales ocasionando enormes gastos en reformatorios y cárceles, haciendo que el Estado sea cada vez más pobre. No hay pobres donde existe un pueblo educado. Fichte afirma con radicalidad: "tengo la esperanza, digo, de poder convencer a algunos alemanes y hacerles comprender que únicamente la educación puede salvarnos de los males que nos oprimen: la barbarie y del salvajismo." (1977, p. 209). La nueva especie humana surge de la educación.

La nación alemana, según Fichte, necesita estadistas con un sólido estudio de la filosofía y de la ciencia en general; estadistas que asuman con seriedad sus obligaciones con un concepto claro del hombre y su futuro, y que entiendan el tiempo presente y comprendan lo que la humanidad presente necesita. Los ciudadanos no necesitan prestar el servicio militar porque todos están preparados y dispuestos a tomar las armas para defender la patria (1977). Según Habermas, opuesto a Fichte, la identidad de una 
nación y de ciudadanía, no debe basarse en rasgos culturales, de idioma o de raza, sino que se trata de compartir de manera igualitaria los derechos de participación y comunicación de las diferentes culturas. El aprendizaje y el aporte es mutuo (Bolívar, 2004).

198 El proyecto educativo de Fichte tiene como vehículo simbólico: la lengua alemana; sin embargo, todos los estados alemanes deben unirse. Además, esta tarea de reformar la educación alemana debe comprometer a los terratenientes, de manera que en sus propiedades se construyan centros educativos dedicados a los hijos de los servidores, es una ventaja que los súbditos sean cultos. También, en las ciudades, son las asociaciones voluntarias las que deben comprometerse en la obra de la educación. Los eruditos deben enseñar en estos centros, hay que buscar a los alumnos, aquellos pobres huérfanos, quienes, después de recibir la educación, se convertirán igualmente en educadores. Se debe dar pan a los pobres, pero al mismo tiempo deben recibir la formación del espíritu. Los maestros deben ser los más competentes, quienes deberán constituir un "seminario de educadores", donde los jóvenes aprendan a enseñar. "Estos centros deben ser autosustentables" (1977, p. 217).

El ciudadano de un Estado totalitario pierde la capacidad de pensar por sí mismo y no actúa pensando en el bien de los otros; para él, lo importante es la obediencia ciega al "mesías salvador" que va a liberar a la nación de todos los enemigos internos y externos. El pueblo se transforma en una masa que es manipulada por una propaganda orientada a dividirla entre amigos y enemigos del sistema, siendo estos últimos eliminados o controlados mediante un método de vigilancia que es renovado constantemente para evitar solidaridades. Sin embargo, la educación de los estados totalitarios ha fracasado, de ahí la singular importancia de una educación intercultural.

\section{EL DESAFÍO DE UNA EDUCACIÓN INTERCULTURAL}

Según Enrique Dussel (2005), hay que relacionar la transmodernidad con la interculturalidad, es decir, hay que establecer un diálogo intercultural transversal con características de multiculturalidad entre grupos humanos que habitan en las periferias. En este contexto, las culturas deben auto valorarse para luego descolonizarse. Este diálogo no es un encuentro de apologistas de sus culturas, se trata de un diálogo SurSur, y no Sur-Norte. Deben dialogar los críticos de cada cultura, los pobres, los marginados, las víctimas. Todos estos diálogos deben incorporarse a los estudios que se llevan a cabo en las universidades y en las diversas organizaciones sociales y culturales.

Sin embargo, el mayor obstáculo para este diálogo, es el sentido competitivo de la economía y la política que conducen a "Si yo vivo, tu no vives, y si tú vives, yo no vivo" (Estermann, 2013, p. 4). El homo economicus reinante en la actualidad, no da paso a que el hombre y la naturaleza se encuentren en un lugar prioritario. El ser humano, en vez de ser un fin último, se ha transformado en un medio; la misma sociedad civil ya no ejerce sus derechos de participación ciudadana, se ha transformado en oferta y demanda de mercado.

Según Raúl Fornet-Betancourt (2016), el sistema hegemónico de la educación contemporánea ha puesto énfasis en la excelencia académica; es el discurso y la aspiración de la mayor parte de universidades en el mundo; todas quieren subir en el ranking mundial. Sin embargo, se ha dejado de lado el servicio a la comunidad y la contribución a la mejora del convivir humano. Ya no se concede valor a la vida, incluso, la pedagogía y las ciencias políticas, diríamos casi todas las ciencias, se han transformado en cómplices de la lógica del capitalismo hegemónico, el cual maneja una 
metodología y una epistemología de dominación. A esto se suma un marketing de publicidad del hombre exitoso y de universidad de excelencia.

En el discurso contemporáneo de la interculturalidad y de la universidad (Estermann \& Tavares, 2015), se sugiere el cambio de universidad por "interversidad", debido a que la misma etimología de universidad (universitas, unum - uno, y verteré girar, convertir) significa "lo uno que gira" (p. 69). Estas definiciones tienen una connotación monocultural y son portadoras de una concepción dominante cuyas manifestaciones son el "saber es poder", el androcentrismo, los títulos académicos, el método dominante de la analiticidad y el alejarse de la sociedad civil. Al contrario, la "interversidad" se ubica en el contexto histórico, cultural, social y político concreto, donde existe una pluralidad epistemológica y metodológica. Urgen estos cambios debido a que el modelo actual de universidad sigue siendo colonial; es el caso de las lenguas ancestrales, las cuales han sido silenciadas por ser consideradas como no válidas para la investigación científica, considerándolas, inclusive, como parte de discursos pertenecientes a la prehistoria de la ciencia. Estos discursos han sido “controlados, seleccionados e incluso marginados por el poder" (Foucault, 1979, p. 11), político, eclesiástico y económico, buscando así instaurar una monocultura pretendidamente científica.

Lamentablemente, en América del Sur, la educación, en todos sus niveles, ha sido controlada por oligarquías y grupos de poder defensores del Estado nacional con cariz totalitario, que han marginado a las diversas culturas, llegando, inclusive, a considerarlas como el "no yo", en el sentido de Fichte, dándoles la categoría de extraños a los pueblos que desde tiempos milenarios han habitado esta tierra.

El asunto de la interculturalidad en las universidades, según Raúl FornetBetancourt, requiere de una "refundación" (Berisso \& Giuliano, 2015, p. 141), lo cual no es asunto solamente de una reestructuración curricular en la universidad, sino que su rol es de transformación social desde una perspectiva intercultural. Las universidades no pueden ser centros de reproducción del sistema colonial, obediente a epistemologías hegemónicas contemporáneas que, entre otras cosas, atraviesan una crisis muy severa.

Frente a esta situación, urge recuperar y profundizar las "epistemologías del Sur", las que se encargaran de elaborar un diagnóstico crítico de la actualidad para, de esta manera, "reconstruir, formular y legitimar alternativas para una sociedad más justa y libre" (De Soussa, 2011, p. 7). Se trata, sobre todo, de favorecer la pluralidad y mermar la influencia de una monoculturalidad que obedece a los intereses de quienes buscan la globalización hegemónica.

El nuevo proyecto educativo debe tener, asimismo, una nueva metodología y una nueva epistemología, unas nuevas maneras de investigar y de pensar, que vayan más allá del sujeto y del objeto, las cuales dejan de lado la pluralidad, la participación y la convivencia (Berisso \& Giuliano, 2015). Hay que pensar e investigar con los otros; para esto hay que des-aprender para re-aprender en el contexto de un proyecto epistémico. El hecho de des-aprender significa deshacerse de lo que significa "lo normal, lo correcto, lo civilizatorio, el progreso." (Handelsman, 2019, p. 12). En esta tarea, se debe procurar que (re) ocupen el espacio público las comunidades que históricamente han sido silenciadas, que nadie hable por ellos, sino que ellos tomen la palabra.

La educación intercultural debe reflexionar sobre las migraciones; cada migrante es portador de sabidurías y conocimientos que pueden aportar al mundo al que llegan pudiendo entablar un diálogo horizontal, donde se puedan descubrir nuevos valores y se haga una valoración crítica de conceptos heredados de la modernidad: democracia, civilización, progreso, y se pueda contemporizar las sabidurías ancestrales. La educación intercultural debe comprometerse con evitar trasplantes de modelos 
universitarios cuyo objetivo principal es "la excelencia", y que determina lo que es científico y lo que no lo es.

El verdadero desafío de una educación intercultural debe velar por la transformación social y política, donde el ser humano se pueda desarrollar plena e integralmente con el fin de crear condiciones para la participación ciudadana en el espacio público mediante un proceso de educación para la acción política (Louzao, 2019). Precisamente, la educación comprometida con la interculturalidad debe promover "el diálogo, el respeto y la convivencia intercultural pero siempre con la inclusión de los excluidos" (Marín, 2013), donde se supere la propuesta homogeneizadora de Fichte, como también se excluya la idea de superioridad de una cultura, o de un idioma sobre otro.

En el campo educativo, urgen políticas que vayan más allá de una simple asimilación, es necesaria la formación de profesorado que sea capaz de comprender y atender la diversidad socio-cultural desde un planteamiento de didácticas y contenidos interculturales en las escuelas. Estos lugares deben promover otro tipo de ciudadanía mediante contenidos y currículos que respondan a problemas sociales y políticos relevantes (Louzao, 2019). El profesorado debe interesarse por conocer y acoger la cultura de sus estudiantes inmigrantes, una predisposición moral y el deseo de estudiar las identidades de cada uno, con una metodología que parta de la práctica para llegar a la teoría para luego volver a la práctica (Leiva, 2012).

\section{CONCLUSIONES}

El idealismo absoluto de Fichte llega a una alta abstracción que corre el riesgo de caer en una especulación imposible de hacerse realidad. Algunos de sus seguidores fanáticos llegaron a considerar la materia como apariencia, y a negar lo sustancial del individuo. Estas abstracciones fueron caldo de cultivo para los socialismos futuros. Luego, también, la obra de Fichte deja la sensación de ser una nostalgia de tiempos pasados de Alemania, de sus glorias pasadas. Fichte es testigo directo de la dominación francesa, entonces emprende un camino de liberación a través de la educación con una inclinación total por el idealismo absoluto, donde el pueblo alemán, su cultura y su idioma son lo prioritario. Cabe recalcar que todo estigma de nación y raza son enormemente nocivos para la sociedad y las familias. Aquí es sumamente necesario que los educadores no tengan una tendencia homogeneizadora sino, más bien, que sean capaces de construir puentes entre las diferentes culturas, de manera que sus integrantes puedan convivir y participar en el espacio público que es de todos. Estos espacios de ciudadanía y de educación, no pueden basarse en un idioma único, o en un rasgo cultural determinado, peor aún, en conceptos de raza; al contrario, deben ser lugares de acogida para las minorías, las cuales son portadoras de diferentes saberes que pueden enriquecer a las culturas que los reciben.

Una verdadera educación intercultural debe valorar y acoger la diversidad lingüística de una sociedad y de una institución educativa. Además, se deben diversificar los contenidos y las metodologías de enseñanza; se debe promover una mentalidad crítica frente a las nuevas tecnologías. Se debe evitar toda clase de asimilación y, más bien, velar por la integración socio-educativa de los alumnos inmigrantes extranjeros, de manera que sean capaces de promover una sociedad critica, participativa, democrática e intercultural. La educación debe velar por la acción política, de ahí que la educación no debe ser orientada únicamente al yo interior, en el caso de Fichte, sino ayudar a que los ciudadanos puedan participar de los debates en el 
espacio público. De ahí que el Estado debe ser plural para reconocer y acoger las diferentes nacionalidades, para mermar las graves asimetrías económicas de un país, y para evitar todo germen de totalitarismo.

En las universidades debe haber un verdadero compromiso de la formación de docentes de manera que sean capaces de elaborar currículos interculturales propios, acordes a la diversidad cultural del medio donde imparten sus cátedras. Debe haber un cambio metodológico en la manera de enseñar y evaluar. La construcción del conocimiento se lleva a cabo mediante la incorporación de diferentes epistemologías provenientes de saberes indígenas y occidentales. De esta manera, se podrá hacer realidad una interculturalidad liberadora y emancipadora.

\section{REFERENCIAS}

ARENDT, H. (2010). Qu' este ce que la politique? Paris : Seuil.

ARENDT, H. (2005). La vie de l'esprit, Paris: Puf.

ARENDT, H. (2002). La condition de l'homme moderne, Paris : Gallimard.

BERISSO, D., \& GIULIANO, F. (2015). La educación como práctica de convivialidad. Una conversación intercultural con Raúl Fornet-Betancourt, Revista del Cisen Tramas/Maepova, Argentina, vol 3, n. 1, pp. 139-151.

BOLIVAR, A. (2004). Ciudadanía y escuela pública en el contexto de diversidad cultural, México: R. M.

CORDOBA, M., VELEZ DE LA CALLE, C. (2015). La alteridad desde la perspectiva de la Transmodernidad de Enrique Dussel, Revista de Latinoamericana de Ciencias Sociales, niñez y juventud, Manizales, vol 14, n. 2, pp. 1001-1015.

DE SOUSA SANTOS, B. (2011). Las epistemologías del sur, Revista Internacional de Filosofía Iberoamericana y Teoría Social, Maracaibo, año16, n. 54, pp. 1-23.

DUSSEL, E. (2018). Siete hipótesis para una estética de la liberación, Praxis, Revista de Filosofia, México, n. 77, pp. 1-28.

DUSSEL, E. (2005). Transmodernidad e interculturalidad, interpretación desde la Filosofía de la Liberación. México. Disponible en: http://red.pucp.edu.pe/ridei/wpcontent/uploads/biblioteca/090514.pdf.

ESTERMANN, J., \& TAVARES, M. (2015). Hacia una interversidad de saberes: Universidad e interculturalidad, Sao Paulo, Revista Lusófona de Educação, v. 31, pp. 65-83.

ESTERMANN, J. (2013). Ecosofía andina: Un paradigma alternativo de convivencia cósmica y de Vivir Bien, Suiza, FAIA, v. 22, n. 9-10, pp. 1-21.

FICHTE, J. B. (1984). Introducciones a la doctrina de la ciencia (Trad. Alianza Editorial), Madrid: Sarpe.

FICHTE, J.B. (1977). Discursos a la nación alemana (Trad. Luis Acosta y María Varela), Barcelona: Orbis.

FORNET-BETANCOURT, R. (2016). La función cultural de la filosofía en tiempos de crisis. Problemata, Revista internacional de filosofia, Portugal, v. 7, n. 3, pp. 203-216.

FORNET-BETANCOURT, R. (2015). De la inculturación a la interculturalidad. Bremem. Disponible en: http://servicioskoinonia.org/relat/355.htm.

FOUCAULT, M. (1979). El orden del discurso, Barcelona: Tusquets.

GIOVANNI, R.; DAREIO, A. (1992). Historia del pensamiento filosófico y científico, Madrid: Herder.

GROVES, T. (2016). Paulo Freire, la educación de adultos y la renovación pedagógica. Revista Tendencias pedagógicas, México, n.27, pp. 1-16.

HANDELSMAN, M. (2019). Decolonizar demanda reaprender. Quito. Disponible en: https://www.elcomercio.com/tendencias/decolonizar-demanda-reaprender-michaelhandelsman.html.

LEIVA, J. (2012). La formación en educación intercultural del profesorado y de la comunidad educativa. Revista Electrónica de Investigación y Docencia, Número monográfico 
(octubre), pp. 8-13, 2012.

LEVINAS, E. (2004). El tiempo y el otro, Barcelona: Paidós.

LOUZAO, M. (2019). Educación intercultural: de la urgencia cuantitativa a la exigencia democrática. Orientaciones para la investigación y la acción en el contexto educativo asturiano. Revista de Investigación en Educación, Oviedo, v. 17, n. 1, pp. 44-54.

202 LUCIO-VILLEGAS. (2015). Paulo Freire. La educación como Instrumento para la justicia social. Revista Internacional de Educación para la Justicia Social, Sevilla, v. 4, n. 1, pp. 9-20.

MARIN, M. A. (2013). La construcción de una ciudadanía intercultural inclusiva: instrumentos para su exploración. Arizona State University Arizona, Estados Unidos, v. 21, pp. 1-25.

SCHMITT, C. (2009). El concepto de lo político, (Trad, R. Agapito), Madrid: Tecnos.

SOUZA, J.F. (2007). La transición posmoderna, derecho y política, Paulo Freire en el tiempo presente, Xativa, 2007, v. 5, pp.223-263. 